\title{
A cross-sectional survey of work and income loss consideration among patients with herpes zoster when completing a quality of life questionnaire
}

Kelly D. Johnson ${ }^{1}$, Susan K. Brenneman ${ }^{2 *}$, Chrisann Newransky ${ }^{1}$, Seth Sheffler-Collins', Laura K. Becker², Angela Belland ${ }^{2}$ and Camilo J. Acosta ${ }^{3}$

\begin{abstract}
Background: Prior research suggests that many patients do not spontaneously include work/income loss when responding to utility assessments, although this remains unconfirmed in the US due to almost no published USbased studies to date, and has not been previously studied among patients with herpes zoster (HZ). The objective of this study was to examine whether patients with $\mathrm{HZ}$ consider work and income loss when completing a quality of life survey.
\end{abstract}

Methods: A cross-sectional survey was administered to 2000 US adult commercial health plan enrollees aged 50-64 years with $\geq 1 \mathrm{HZ}$ medical claim during 2014. The survey collected information related to health status (EQ-5D), work productivity, and HZ severity and clinical features.

Results: Mean respondent age was 58.4 years [standard deviation (SD) 4.1] and 62.0\% were female. About 3 in 4 (76.8\%) patients $(N=772)$ were employed either full $(69.9 \%)$ or part time (6.9\%). Less than half $(45 \%)$ spontaneously considered work/income loss when responding to EQ-5D, and mean EQ-5D scores for patients who considered work/ income loss were lower than for patients who did not [0.56 ( $S D=0.28)$ vs. $0.69(S D=0.24) ; p<0.001]$. Overall, $43 \%$ of patients reported at least one full day missed (mean $=9$ full days) and $29 \%$ reported at least one partial day missed (mean $=6$ partial days) during the most recent shingles episode. Patients who considered work loss were more likely to have missed full $(76.4 \%$ vs $26.0 \%, p<0.001)$ or partial $(70.9 \%$ vs. $35.2 \%, p<0.001)$ days. Patients with absenteeism were more likely to consider work/income loss when completing EQ-5D [odds ratio (OR) $=7.91,95 \%$ confidence interval (CI) 5.01-12.31]. Odds of absenteeism/presenteeism increased significantly with increasing levels of $\mathrm{HZ}$ severity, and higher odds were associated with pain located on the face/scalp/neck/eye/ear (OR 1.90, 95\% Cl 1.06-3.40) and with pain lasting $12+$ months ( $O R=2.91,95 \% \mathrm{Cl} 1.14-7.42)$.

Conclusions: $\mathrm{HZ}$ has considerable impact on the work and productivity of adults aged 50-64 years old. However, many patients with $\mathrm{HZ}$ do not spontaneously consider work/income loss when completing a standardized quality of life questionnaire. Studies that use health state utilities in $\mathrm{HZ}$ based on EQ-5D may not fully reflect the societal costs of work loss.

Keywords: Herpes zoster, Quality of life, Work loss, Income loss, Productivity

\footnotetext{
* Correspondence: susan.brenneman@optum.com

${ }^{2}$ Health Economics and Outcomes Research, Optum, 11000 Optum Circle,

Eden Prairie, MN 55344, USA

Full list of author information is available at the end of the article
}

(c) The Author(s). 2018 Open Access This article is distributed under the terms of the Creative Commons Attribution 4.0 International License (http://creativecommons.org/licenses/by/4.0/), which permits unrestricted use, distribution, and reproduction in any medium, provided you give appropriate credit to the original author(s) and the source, provide a link to the Creative Commons license, and indicate if changes were made. The Creative Commons Public Domain Dedication waiver (http://creativecommons.org/publicdomain/zero/1.0/) applies to the data made available in this article, unless otherwise stated. 


\section{Background}

Herpes Zoster (HZ) ("shingles") results from the reactivation of varicella-zoster virus located in sensory ganglia. Usually $\mathrm{HZ}$ is acute and patients experience mild to moderate pain that can have substantial physical and psychological impact. About 10-15\% of patients with HZ subsequently develop post-herpetic neuralgia (PHN), a persistent, chronic neuropathic pain [1]. The estimated overall annual cost of HZ in US (2013) among persons aged 50 or older has been estimated at $\$ 1.85$ billion (B) in direct costs and an additional $\$ 3.2 \mathrm{~B}$ in indirect costs, including productivity loss [2]. Work loss ("absenteeism") per HZ episode is reported by $50-64 \%$ of patients, with $51-76 \%$ reporting reduced productivity at work ("presenteeism") [3, 4]. HZ has a negative impact on patient quality of life, regardless of patient age [5-8].

An $\mathrm{HZ}$ vaccine (Zostavax ${ }^{\oplus}$ ) was licensed by the US FDA in 2006 and is recommended for routine use among adults aged 60 and older by the US Centers for Disease Control and Prevention (CDC) Advisory Committee on Immunization Practices (ACIP) [9, 10]. Zostavax ${ }^{\bullet}$ was also approved for use among adults aged 50-59 years in 2011, but routine use is not currently recommended by the ACIP. Although several studies have demonstrated a sharply continuing rise in incidence of $\mathrm{HZ}$ beyond age 50 [11-13] evidence is lacking regarding cost-effectiveness of $\mathrm{HZ}$ vaccination among persons aged 50-59 years. HZ episodes are generally less severe for younger age groups, so the benefits of $\mathrm{HZ}$ vaccination may be more difficult to demonstrate. Even so, patients who are 50-59 years of age may be more likely to have $\mathrm{HZ}$ impact their work and productivity than older patients; $72.1 \%$ of persons aged $50-59$ years were employed in the US in 2015, compared to $28.4 \%$ of those aged 60 years or older [14].

Research suggests that many patients do not spontaneously include work/income loss when responding to utility assessments [15]. Therefore, health-state utility evaluation, including those based on standardized scales such as the EuroQol Five Dimensions Questionnaire (EQ-5D) $[16,17]$, may not fully reflect the impact of work loss. Consequently, it may be appropriate to account for this effect separately in the cost calculations [18]. A review of the literature regarding work/income loss consideration in health-state utility assessments across health conditions indicates mixed findings [19-28]. The most recent systematic review on this topic was published in 2010, and it concluded that more empirical work was required on the topic using generic quality of life instruments and larger samples [15]. Furthermore, almost all assessments of the relationship between work/income loss consideration and health-state utilities have been conducted outside the US. Since public/private social safety nets (e.g. paid sick leave, unemployment, etc.) may differ greatly by country, assessing country-specific utility values are crucial [29]. Overall, whether consideration of lost income is included in health state valuations (and subsequent economic evaluations) in the US remains largely unknown.

The primary objective of this study was to examine whether patients who have experienced $\mathrm{HZ}$ consider income and productivity loss when completing a generic quality of life survey. Secondary objectives included the following: 1. to assess the impact of $\mathrm{HZ}$ on absenteeism or presenteeism among working adults; and 2. to assess the associations among EQ-5D scores, the severity of $\mathrm{HZ}$, whether a patient experiences absenteeism or presenteeism, and whether the patient considers income and productivity loss when completing EQ-5D.

\section{Methods \\ Study design}

This study was a cross-sectional survey which utilized the Optum research database of medical and pharmacy claims linked to enrollment information to identify patients with HZ. Following identification, eligible patients were invited by mail to participate in the survey.

\section{Sample size}

To estimate the sample size of subjects required for the survey portion of the study, the primary outcome measure was assumed to be the proportion of survey respondents that indicated they considered work and/or income loss when completing the first presentation of the EQ-5D. A target sample size was determined by the value and desired precision of measured proportions for this outcome variable. Because the actual proportions were unknown, the largest sample size required for a precision of \pm 0.05 for all values of proportions was targeted $(n=385)$. Assuming a $20 \%$ response rate a priori, 2000 patients were contacted to participate in the survey to obtain an evaluable sample of at least 400 completed patient surveys.

\section{Study population}

Patients aged 50-64 years were identified via at least 1 claim with an International Classification of Diseases, Ninth Revision, Clinical Modification (ICD-9-CM) code for $\mathrm{HZ}$ (053.0-053.9) in any position between January 1, 2014 and December 31, 2014. The first qualifying HZ claim was identified as the index claim, and the date of that first claim was the index date. Patients were required to have continuous health plan enrollment 9 months prior to and 3 months subsequent to the index date. From this preliminary patient population, 2000 patients were selected to receive the study survey as follows. To ensure a study sample of patients that included more severe $\mathrm{HZ}$, all eligible patients with evidence of nervous system complications (ICD-9-CM 053.1x) and/ 
or eye complications (ICD-9-CM 053.2x, 053.71) were automatically included in the final sample of 2000 and were categorized as "more severe" patients. Patients from the remaining preliminary population (ICD-9-CM 053.0, 053.8, 053.79, 053.9) were categorized as "less severe" and were randomly selected to complete the final surveyed sample of 2000 patients. Identified patients were invited by mail to participate, and a process for mailed surveys developed by Dillman et al. was followed [30].

\section{Survey-based data}

The data collection instrument included questions related to demographic and $\mathrm{HZ}$ clinical characteristics, health status (EQ-5D questions regarding dimensions of mobility, self-care, usual activities, pain/discomfort, anxiety/depression, with answers describing no, moderate, or extreme impairment; and overall health state scale) $[16,17]$, and work experience during the most recent HZ episode. Patient demographic characteristics included marital status (married/living with partner, widowed, divorced, separated, never married), highest level of education, employment status, race, and income. $\mathrm{HZ}$ clinical characteristics included severity (very mild, mild, moderate, severe, or very severe), worst level of pain experienced (11-point scale; $0=$ no pain and $10=$ worst possible pain), duration of pain (scale ranging from $<1$ week to $\geq 12$ months) and location of $\mathrm{HZ}$ outbreak (obtained via indication on a body figure drawing). The EQ-5D [16, 17] was presented with instructions that advised the patient to recall a day during the most recent shingles episode and answer health state questions as he/she would have on that day. Survey questions regarding work experience included number of full or partial days missed (absenteeism), rating of effectiveness (presenteeism) at work ( $0 \%$ "not effective at all" to $100 \%$ "completely effective"), reasons for absence, and use of paid sick, vacation or disability days.

\section{Primary and secondary outcome measures}

The primary outcome variable was calculated as the proportion of patients who answered that they considered work/income loss when responding to EQ-5D questions. Secondary outcomes included the EQ-5D index scores, absenteeism and presenteeism. EQ-5D health states were converted into a single summary index by applying weights to each of the levels $(1=$ no problems, $2=$ some problems, 3 = extreme problems) in each dimension according to the standard instructions provided by the EuroQoL Group [31]. An EQ-5D summary index was calculated for each subject. For each EQ-5D dimension, dichotomous variables were created indicating whether it was at least a moderate problem or a severe problem. These variables were combined to create 16 utility factors, which were multiplied by a US-specific preference weight, aggregated, and subtracted from 1 to form utility scores. If any dimension was missing, the utility score was assigned a missing value. The tariff used to transfer the EQ-5D to utility scores was based on Shaw et al. representing a US population using the time trade-off (TTO) technique [32]. The proportion of patients who experienced absenteeism or presenteeism was calculated. Absenteeism was defined as patient self-reporting of at least 1 entire or 1 partial day of work loss due to shingles, while presenteeism was defined as self-reported effectiveness at work of $\leq 70 \%$. No work loss was defined as patient self-reported effectiveness at work as $80-100 \%$ and no reported full or partial lost work days.

\section{Claims-based data captured}

Following completion of survey data collection, pharmacy and medical claims data for the 9 months preceding and 3 months following the index date were extracted and merged to the survey data. Baseline demographic characteristics included patient age (calculated as of index year), gender, and geographic region. Baseline clinical characteristics (during a baseline period of 9 months period preceding the index date) included the Quan-Charlson comorbidity score [33], which was calculated for each patient to measure overall comorbidity burden, and comorbid chronic conditions, identified using ICD-9-CM codes and the Clinical Classification software managed by AHRQ [34]. Indicator variables corresponding to specific HZ ICD-9-CM codes were created using medical claims during the study identification period in order to capture $\mathrm{HZ}$ complications. $\mathrm{HZ}$ treatment with antiviral medication during the 3-month period following the index date was also assessed.

\section{Statistical analysis}

The analytic population consisted of all survey respondents with completed surveys, including all EQ-5D items. Descriptive statistics were calculated for all measures, including means, medians, and standard deviations (SD) for continuous variables and frequency distributions for categorical variables. Bivariate comparisons of patient characteristics included t-tests for continuous measures and chi-squared tests for categorical measures. Multivariate analysis was conducted using regression models appropriate for each dependent variable assessed based on the distribution of the measure. For each model, specific predictors to be included were determined based upon clinical rationale and statistical significance. Consideration of work/income loss (yes/no) as the dependent variable was modeled using logistic regression to assess the impact of actual absenteeism or presenteeism, adjusted for $\mathrm{HZ}$ severity, pain location and duration; employment status; age; and gender. 
Absenteeism/presenteeism vs. no work loss as the dependent variable was also modeled using logistic regression, and covariates included $\mathrm{HZ}$ severity, pain location and duration, employment status, age, and gender.

\section{Regulatory considerations}

All data were used in compliance with state and federal regulations related to the privacy and security of individually identifiable health information, including the Health Insurance Portability and Accountability Act (HIPAA) Standards for Privacy of Individually Identifiable Health Information. Independent study approval was obtained from the New England Institutional Review Board and a waiver of documentation of informed consent was granted. The mailed study packet informed patients that their consent for participation was implied by returning the completed survey.

\section{Results}

Among 19,128 patients with at least one HZ claim during the calendar year 2014, 5603 met all study entry criteria (Fig. 1). From this preliminary population, 2000 patients (1018 severe and 982 less severe) were selected as described above to receive the study survey. A total of 772 patients completed the survey, corresponding to an overall response rate of $43 \%$. This response rate was calculated using methods described by the American Association for Public Opinion Research [35].

Baseline patient characteristics are included in Table 1. Mean age overall was 58.4 years (SD 4.1 ) and $62.0 \%$ were female. Most patients (90.9\%) were white and the

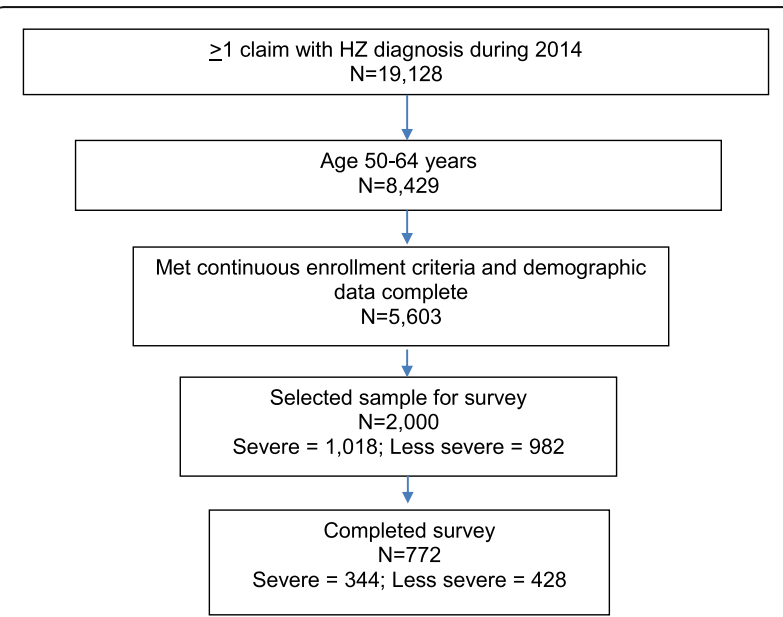

Fig. 1 Survey sample and cohort attrition. Includes a flowchart diagram illustrating the study population identification and survey sample selection process. The flowchart begins with the total number of preliminarily eligible patients with $\geq 1$ administrative claim with an HZ diagnosis during $2014(N=19,128)$, and depicts the number of patients selected at each step of the cohort identification and survey administration process to result in a final study sample of 772 patients
Table 1 Baseline patient demographic and clinical characteristics

\begin{tabular}{|c|c|}
\hline \multicolumn{2}{|l|}{ Characteristic } \\
\hline $\bar{N}$ & 772 \\
\hline Age, mean (SD) & $58.4(4.1)$ \\
\hline Female, $n(\%)$ & $478(62.0)$ \\
\hline \multicolumn{2}{|l|}{ Race/ethnicity, n (\%) } \\
\hline American Indian/Native Alaskan & $7(0.9)$ \\
\hline Asian/Pacific Islander & $18(2.3)$ \\
\hline Black or African American & $30(3.9)$ \\
\hline White & $700(90.9)$ \\
\hline Other & $21(2.7)$ \\
\hline Hispanic/Latino & $35(4.6)$ \\
\hline Married/Living with Partner, $n$ (\%) & $606(78.5)$ \\
\hline \multicolumn{2}{|l|}{ Employment status, $n$ (\%) } \\
\hline Full-time employment & $536(69.9)$ \\
\hline Part-time employment & $53(6.9)$ \\
\hline Not employed/working for pay & $28(3.7)$ \\
\hline Retired & $98(12.8)$ \\
\hline Homemaker & $52(6.8)$ \\
\hline \multicolumn{2}{|l|}{ Income, $n$ (\%) } \\
\hline Less than $\$ 25,000$ & $36(4.9)$ \\
\hline$\$ 25,000-\$ 49,999$ & $122(16.7)$ \\
\hline$\$ 50,000-\$ 74,999$ & $167(22.8)$ \\
\hline$\$ 75,000-\$ 99,999$ & $115(15.7)$ \\
\hline More than $\$ 100,000$ & $292(39.9)$ \\
\hline Any claims-based evidence of $\mathrm{HZ}$ treatment & $551(71.4)$ \\
\hline Acyclovir & $156(20.2)$ \\
\hline Famciclovir & $44(5.7)$ \\
\hline Valacyclvir & $370(47.9)$ \\
\hline \multicolumn{2}{|l|}{ Identification diagnosis code (ICD-9-CM), n (\%) } \\
\hline 053.0; Herpes zoster with meningitis & $4(0.5)$ \\
\hline 053.1 $x_{i}$ Herpes zoster with nervous system complications & $247(32.0)$ \\
\hline 053.2x; Herpes zoster with eye complications & $178(23.1)$ \\
\hline 053.7x; Herpes zoster with ear complications & $14(1.8)$ \\
\hline 053.71; Otitis externa due to herpes zoster & $2(0.3)$ \\
\hline 053.79; Other specified herpes zoster complications & $12(1.6)$ \\
\hline 053.8; Unspecified herpes zoster complication & $9(1.2)$ \\
\hline 053.9; Herpes zoster without mention of complication & $572(74.1)$ \\
\hline
\end{tabular}

majority were married with at least a high school education. About 3 in 4 (76.8\%) were employed either full(69.9\%) or part-time $(6.9 \%)$. Within 3 months of the index date, $71.4 \%$ of respondents had evidence of $\mathrm{HZ}$ antiviral therapy. The most commonly used agent was valacyclovir. Overall, $34.6 \%$ of patients rated their $\mathrm{HZ}$ as severe or extremely severe (Table 2); $32.0 \%$ of patients had $\mathrm{HZ}$ with nervous system complications, and $23.1 \%$ 
Table 2 Patient-reported herpes zoster characteristics stratified by consideration of work/income loss

\begin{tabular}{|c|c|c|c|c|c|c|c|c|c|c|}
\hline \multirow[b]{2}{*}{ Herpes Zoster Severity } & \multicolumn{3}{|c|}{$\begin{array}{l}\text { Total }^{a} \\
(N=772,100 \%)\end{array}$} & \multicolumn{3}{|c|}{$\begin{array}{l}\text { Considered }=\text { YES } \\
(N=347,44.9 \%)\end{array}$} & \multicolumn{3}{|c|}{$\begin{array}{l}\text { Considered = NO } \\
(N=425,55.1 \%)\end{array}$} & \multirow[t]{2}{*}{$p$-value } \\
\hline & valid $N$ & $n$ & $\%$ & valid $N$ & $n$ & $\%$ & valid $N$ & $n$ & $\%$ & \\
\hline Very mild & 769 & 108 & 14.04 & 345 & 31 & 8.99 & 424 & 77 & 18.16 & $<0.001$ \\
\hline Mild & 769 & 156 & 20.29 & 345 & 47 & 13.62 & 424 & 109 & 25.71 & $<0.001$ \\
\hline Moderate & 769 & 239 & 31.08 & 345 & 115 & 33.33 & 424 & 124 & 29.25 & 0.223 \\
\hline Severe & 769 & 192 & 24.97 & 345 & 105 & 30.43 & 424 & 87 & 20.52 & 0.002 \\
\hline Extremely severe & 769 & 74 & 9.62 & 345 & 47 & 13.62 & 424 & 27 & 6.37 & $<0.001$ \\
\hline Length of time pain lasted categories & valid $N$ & $n$ & $\%$ & valid $N$ & $n$ & $\%$ & valid $N$ & $n$ & $\%$ & \\
\hline Less than 1 month & 770 & 383 & 49.74 & 347 & 154 & 44.38 & 423 & 229 & 54.14 & 0.007 \\
\hline 1 to less than 3 months & 770 & 215 & 27.92 & 347 & 101 & 29.11 & 423 & 114 & 26.95 & 0.507 \\
\hline 3 months to less than 6 months & 770 & 61 & 7.92 & 347 & 29 & 8.36 & 423 & 32 & 7.57 & 0.685 \\
\hline 6 months to less than 12 months & 770 & 42 & 5.45 & 347 & 21 & 6.05 & 423 & 21 & 4.96 & 0.509 \\
\hline $12+$ months & 770 & 69 & 8.96 & 347 & 42 & 12.10 & 423 & 27 & 6.38 & 0.006 \\
\hline \multicolumn{11}{|l|}{ Location of pain ${ }^{b}$} \\
\hline Face/Scalp/Neck/Eye/Ear & 771 & 326 & 42.28 & 346 & 161 & 46.53 & 425 & 165 & 38.82 & 0.031 \\
\hline Shoulder/Upper Arm/Elbow/Forearm/Hand & 771 & 106 & 13.75 & 346 & 43 & 12.43 & 425 & 63 & 14.82 & 0.337 \\
\hline Chest/Abdomen/Upper Back/Lower Back & 771 & 387 & 50.19 & 346 & 169 & 48.84 & 425 & 218 & 51.29 & 0.499 \\
\hline Groin area/Buttocks & 771 & 71 & 9.21 & 346 & 40 & 11.56 & 425 & 31 & 7.29 & 0.042 \\
\hline \multirow[t]{2}{*}{ Thigh/Knee/Shin/Calf/Ankle/Foot } & 771 & 76 & 9.86 & 346 & 34 & 9.83 & 425 & 42 & 9.88 & 0.979 \\
\hline & $n$ & mean & SD & $n$ & mean & SD & $n$ & mean & SD & \\
\hline Average level of pain & 772 & 5.60 & 2.57 & 347 & 6.23 & 2.60 & 425 & 5.08 & 2.43 & $<0.001$ \\
\hline Worst level of pain & 769 & 7.15 & 2.71 & 346 & 7.79 & 2.50 & 423 & 6.61 & 2.76 & $<0.001$ \\
\hline
\end{tabular}

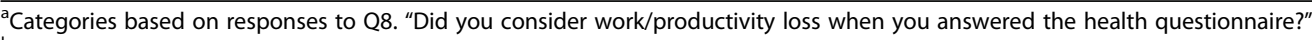

${ }^{\mathrm{b}}$ Subjects can report more than one location

had HZ with eye complications, based on ICD-9-CM diagnosis codes from claims data (Table 1).

\section{Primary outcome: Work/income loss consideration}

Fewer than half $(44.9 \%)$ of survey respondents indicated that they considered work/income loss when answering EQ-5D questions (Table 2). Patients who considered work/income loss reported greater severity of $\mathrm{HZ}$, were more likely to have pain lasting $>12$ months and less likely to have pain lasting $<1$ month, have HZ located on face/scalp/neck/head or groin/buttocks, and have higher mean pain levels. Mean EQ-5D scores for those who reported that they did consider work/income loss were significantly lower than for patients who reported they did not consider [0.56 (SD 0.28) vs 0.69 (SD 0.24), $p<0.001$ ] (Table 3). Significant differences were observed across all domains, but the largest impacts were observed for the 'usual activities' domain (level 3 $=27.2 \%$ vs $7.8 \%, p<0.001)$ and the 'pain/discomfort' domain (level $3=43.6 \%$ vs $24.4 \%, p<0.001$ ). Patients with absenteeism during the $\mathrm{HZ}$ episode were more likely to consider work/income loss when completing the EQ-5D [odds ratio (OR) $=7.91,95 \%$ confidence interval (CI) 5.01-12.31] (Fig. 2). Presenteeism during the $\mathrm{HZ}$ episode was not significantly associated with consideration of work/income loss $(\mathrm{OR}=1.09,95 \% \mathrm{CI}$ $0.55-2.16)$.

\section{Secondary outcomes: Absenteeism and presenteeism}

Overall, $43.3 \%(n=334)$ of patients reported at least one full day missed (mean $=9$ full days) and $29.4 \%$ $(n=227)$ reported at least one partial day missed (mean $=6$ partial days) (Additional file 1: Appendix 1); 433 patients $(56.1 \%)$ reported at least one full or partial day of lost work (Table 3). Among the 695 patients that reported their effectiveness at work, only $19.1 \%$ were $100 \%$ effective during their $\mathrm{HZ}$ episode. There were 375 respondents $(54.0 \%)$ who met the presenteeism definition $(\leq 70 \%)$. Patients who considered work loss were more likely to have missed full $(76.4 \%$ vs $26.0 \%, p<0.001)$ or partial (70.9\% vs. $35.2 \%, p<0.001)$ days: $38.3 \%$ used sick days, $11.8 \%$ vacation, and $2.2 \%$ disability. Most common reasons for absence were the following: too uncomfortable (39.3\%), too much pain (38.3\%), and healthcare visits (34.6\%). Mean EQ-5D scores for those who reported no work loss [0.79 (SD 0.18)] were higher than those with absenteeism [0.56 (SD 0.27)] or 
Table 3 EQ-5D scores* stratified by work loss consideration and absenteeism/presenteeism

\begin{tabular}{|c|c|c|c|c|c|c|c|c|}
\hline & $\begin{array}{l}\text { Total } \\
(n=772)\end{array}$ & $\begin{array}{l}\text { Considered Work } \\
\text { Loss }(n=347)\end{array}$ & $\begin{array}{l}\text { Did Not Consider } \\
\text { Work Loss }(n=425)\end{array}$ & $p$ value & $\begin{array}{l}\text { Absenteeism } \\
(n=433)\end{array}$ & $\begin{array}{l}\text { Presenteeism only } \\
(n=78)\end{array}$ & $\begin{array}{l}\text { No work loss } \\
(n=222)\end{array}$ & $p$-value \\
\hline Index Score, mean (SD) & $0.63(0.27)$ & $0.56(0.28)$ & $0.69(0.24)$ & $<0.001$ & $0.56(0.27)$ & $0.62(0.25)$ & $0.79(0.18)$ & $<0.001$ \\
\hline \multicolumn{9}{|l|}{ Mobility, n (\%) } \\
\hline Level 1 & $551(71.7)$ & $219(63.5)$ & $332(78.5)$ & $<0.001$ & $281(65.4)$ & $53(68.0)$ & $193(87.3)$ & $<0.001$ \\
\hline Level 2 & $164(21.4)$ & $93(27.0)$ & $71(16.8)$ & $<0.001$ & $107(24.9)$ & $22(28.2)$ & $25(11.3)$ & $<0.001$ \\
\hline Level 3 & $53(6.9)$ & $33(9.6)$ & $20(4.7)$ & 0.009 & $42(9.8)$ & $3(3.9)$ & $3(1.4)$ & $<0.001$ \\
\hline \multicolumn{9}{|l|}{ Self-Care, $n(\%)$} \\
\hline Level 1 & $596(77.5)$ & $244(70.5)$ & $352(83.2)$ & $<0.001$ & $310(71.9)$ & $57(73.1)$ & $202(91.4)$ & $<0.001$ \\
\hline Level 2 & $158(20.6)$ & $94(27.2)$ & $64(15.1)$ & $<0.001$ & $111(25.8)$ & $20(25.6)$ & $18(8.1)$ & $<0.001$ \\
\hline Level 3 & $15(2.0)$ & $8(2.3)$ & $7(1.7)$ & 0.512 & $10(2.3)$ & $1(1.3)$ & $1(0.5)$ & 0.200 \\
\hline \multicolumn{9}{|l|}{ Usual activities, n (\%) } \\
\hline Level 1 & $316(41.1)$ & $83(24.0)$ & $233(55.1)$ & $<0.001$ & $113(26.2)$ & $27(34.6)$ & $162(73.3)$ & $<0.001$ \\
\hline Level 2 & $326(42.4)$ & $169(48.8)$ & $157(37.1)$ & 0.001 & $211(49.0)$ & $43(55.1)$ & $55(24.9)$ & $<0.001$ \\
\hline Level 3 & $127(16.5)$ & $94(27.2)$ & $33(7.8)$ & $<0.001$ & $107(24.8)$ & $8(10.3)$ & $4(1.8)$ & $<0.001$ \\
\hline \multicolumn{9}{|l|}{ Pain/Discomfort, $n$ (\%) } \\
\hline Level 1 & $64(8.3)$ & $24(7.0)$ & $40(9.5)$ & 0.217 & $16(3.7)$ & $2(2.6)$ & $45(20.4)$ & $<0.001$ \\
\hline Level 2 & $450(58.7)$ & $170(49.4)$ & $280(66.2)$ & $<0.001$ & $225(52.2)$ & $51(66.2)$ & $153(69.2)$ & $<0.001$ \\
\hline Level 3 & $253(33.0)$ & $150(43.6)$ & $103(24.4)$ & $<0.001$ & $190(44.1)$ & $24(31.2)$ & $23(10.4)$ & $<0.001$ \\
\hline \multicolumn{9}{|l|}{ Anxiety/Depression, $n$ (\%) } \\
\hline Level 1 & $383(49.7)$ & $147(42.5)$ & $236(55.7)$ & $<0.001$ & $187(43.3)$ & $31(39.7)$ & $151(68.3)$ & $<0.001$ \\
\hline Level 2 & $327(42.5)$ & $161(46.5)$ & $166(39.2)$ & 0.039 & $201(46.5)$ & $40(51.3)$ & $65(29.4)$ & $<0.001$ \\
\hline Level 3 & $60(7.8)$ & $38(11.0)$ & $22(5.2)$ & 0.003 & $44(10.2)$ & $7(9.0)$ & $5(2.3)$ & 0.001 \\
\hline
\end{tabular}

*Level 1 = not impacted; Level 2 = moderately impacted; Level 3 = severely impacted

presenteeism [0.62 (SD 0.25)] $(p<0.001)$ (Table 3). While significant differences were observed across all EQ-5D domains, the largest impact of absenteeism/presenteeism was observed for 'usual activities' and 'pain/discomfort'.

Among the entire study cohort, the odds of absenteeism/presenteeism increased significantly with increasing levels of HZ severity (Table 4). Higher odds of absenteeism/presenteeism were associated with pain located on the face/scalp/neck/eye/ear (OR $=1.90,95 \%$ CI 1.06 3.40). The odds of absenteeism/presenteeism were higher among those with pain lasting $12+$ months (OR $=2.91,95 \%$ CI $1.14-7.42)$ or those who were currently employed ( $\mathrm{OR}=1.66,95 \% \mathrm{CI} 1.06-2.61)$, and were lower among males $(\mathrm{OR}=0.58,95 \% \mathrm{CI} 0.40-0.84)$. Among the employed subset of patients, results were similar to those observed in the entire cohort with respect to the effect of $\mathrm{HZ}$ severity on absenteeism/presenteeism and male gender. However, among the employed subset, there was a marginal effect of pain located on the face/ scalp/neck/eye/ear.

\section{Discussion}

Fewer than half of survey respondents with $\mathrm{HZ}$ indicated they considered work/income loss when responding to EQ-5D items, and EQ-5D scores were significantly associated with consideration of income loss. Patients that did consider work/income loss were more significantly impacted by their HZ. They reported more severe $\mathrm{HZ}$, pain lasting more than 12 months, location of $\mathrm{HZ}$ on face, neck or scalp, and higher pain levels. More than half of patients with $\mathrm{HZ}(56.1 \%)$ reported at least one full or partial day of lost work due to $\mathrm{HZ}$ during the most recent shingles episode. Patients with absenteeism during their $\mathrm{HZ}$ episode were almost 8 times more likely to consider work/income loss when completing the EQ-5D.

As noted, among our study population of patients with predominantly (65\%) mild to moderate $\mathrm{HZ}, 45 \%$ did not incorporate consideration of work or income loss in their EQ-5D response. Published research of patient work/income loss consideration for health-state utility assessment, conducted almost exclusively ex-US, indicates mixed evidence, as a majority of previous studies which have examined this issue across disease states report that fewer than $50 \%$ of respondents considered impact of work/income loss [19-26], while 2 studies found that most study participants considered work/income loss [27, 28]. Previous study results are mixed as to whether lost income affects utility scores, with income consideration more often associated with lower utilities 


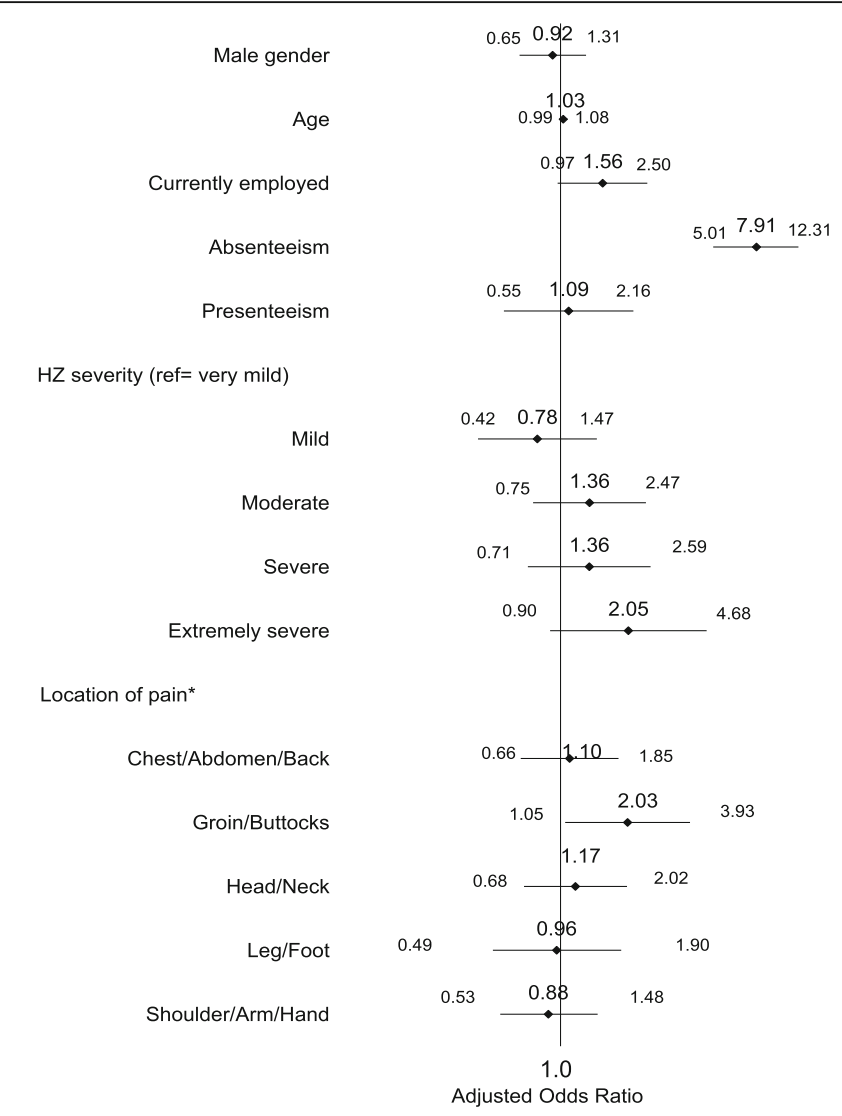

*Patients may report more than 1 pain location. Model also adjusted for duration of $\mathrm{HZ}$ pain (not a significant predictor).

Fig. 2 Odds of work/income loss consideration when completing EQ-5D. Illustrates the adjusted odds ratios of work/income loss consideration when completing the EQ-5D. Patients with absenteeism during the $\mathrm{HZ}$ episode were more likely to consider work/income loss when completing the $\mathrm{EQ}-5 \mathrm{D}(\mathrm{OR}=7.91,95 \% \mathrm{Cl} 5.01-12.31)$, while presenteeism was not significantly associated with consideration of work/income loss $(\mathrm{OR}=1.09$, $95 \% \mathrm{Cl} 0.55-2.16)$

for severely impaired health states and not mild [15, 19, 20, 28, 36]. In the US, Meltzer and colleagues requested 402 subjects to value back pain and 429 subjects to value blindness using the TTO method, and concluded that the economic costs of illness are not likely to be reflected in quality of life questions and should be counted separately [37]. However, since the study was only published in abstract form, with limited information provided regarding the survey method, the scale of TTO values, and background characteristics of the study sample [15], the generalizability and validity of the study's findings to the association between work/income loss and health-state utilities in the US may be questionable.

A significant difference in mean EQ-5D index scores between the respondents in our study who did consider and did not consider work and/or income loss (0.56 vs. 0.69 , respectively; $p<0.001$ ) was observed, and respondents who considered work/income loss also reported greater $\mathrm{HZ}$ severity and duration of pain. These findings reflect the impact of $\mathrm{HZ}$ on health status that has previously been reported in the literature. Generally, studies which have employed the EQ-5D among patients with $\mathrm{HZ}$ have found an inverse association between health-related quality of life and levels of reported pain [38-40], with the poorest quality of life observed among patients with PHN $[38,39]$. Across 6 European countries, van Seventer et al. examined the relationship between severity of PHN and health-related utility (EQ-5D), and found decreasing mean EQ-5D index scores among patients with mild, moderate and severe pain, respectively $($ mean EQ-5D: mild $=0.72$, moderate $=$ 0.63 , and severe $=0.27$ ) $[40]$.

In the current study, $56.1 \%$ of patients with $\mathrm{HZ}$ reported at least one full or partial day of lost work due to HZ. Patients with absenteeism during their HZ episode were about 7.9 times more likely to consider work/income loss when completing the EQ-5D than were 
Table 4 Odds of absenteeism/presenteeism vs. no work loss (entire cohort, employed subset)

\begin{tabular}{|c|c|c|c|c|c|c|c|c|}
\hline \multirow[t]{2}{*}{ Independent Variables } & \multicolumn{4}{|c|}{$\begin{array}{l}\text { Absent/Present vs. No Work loss, } \\
\text { Entire Cohort }(N=722)\end{array}$} & \multicolumn{4}{|c|}{$\begin{array}{l}\text { Absent/Present vs. No Work loss, } \\
\text { Employed Subset }(N=584)\end{array}$} \\
\hline & odds ratio & lower 95\% Cl & upper 95\% Cl & $p$-value & odds ratio & lower 95\% Cl & upper 95\% Cl & $p$-value \\
\hline \multicolumn{9}{|l|}{ Herpes Zoster Severity } \\
\hline Very mild & ref. & - & - & - & ref. & - & - & - \\
\hline Mild & 2.396 & 1.401 & 4.098 & 0.001 & 2.872 & 1.562 & 5.281 & $<0.001$ \\
\hline Moderate & 5.707 & 3.312 & 9.834 & $<0.001$ & 6.683 & 3.593 & 12.430 & $<0.001$ \\
\hline Severe & 7.279 & 3.880 & 13.658 & $<0.001$ & 9.293 & 4.478 & 19.284 & $<0.001$ \\
\hline Extremely severe & 8.988 & 3.562 & 22.680 & $<0.001$ & 21.341 & 5.469 & 83.271 & $<0.001$ \\
\hline \multicolumn{9}{|l|}{ Location of pain ${ }^{a}$} \\
\hline Shoulder/Upper Arm/Elbow/Forearm/Hand & 0.831 & 0.488 & 1.415 & 0.496 & 0.858 & 0.450 & 1.636 & 0.643 \\
\hline Thigh/Knee/Shin/Calf/Ankle/Foot & 0.809 & 0.397 & 1.652 & 0.561 & 0.811 & 0.365 & 1.801 & 0.607 \\
\hline Face/Scalp/Neck/Eye/Ear & 1.895 & 1.056 & 3.399 & 0.032 & 1.955 & 0.997 & 3.832 & 0.051 \\
\hline Chest/Abdomen/Upper Back/Lower Back & 1.474 & 0.852 & 2.550 & 0.166 & 1.553 & 0.827 & 2.916 & 0.171 \\
\hline Groin area/Buttocks & 1.621 & 0.766 & 3.429 & 0.206 & 1.192 & 0.522 & 2.722 & 0.676 \\
\hline \multicolumn{9}{|l|}{ Length of time pain lasted categories } \\
\hline Less than 1 month & ref. & - & - & - & ref. & - & - & - \\
\hline 1 to less than 3 months & 1.490 & 0.952 & 2.334 & 0.081 & 1.416 & 0.850 & 2.357 & 0.181 \\
\hline 3 months to less than 6 months & 1.493 & 0.705 & 3.162 & 0.295 & 2.259 & 0.854 & 5.970 & 0.100 \\
\hline 6 months to less than 12 months & 1.412 & 0.521 & 3.827 & 0.498 & 1.306 & 0.406 & 4.198 & 0.655 \\
\hline $12+$ months & 2.907 & 1.140 & 7.415 & 0.025 & 0.803 & 7.854 & 0.114 & 0.803 \\
\hline Currently employed & 1.664 & 1.062 & 2.609 & 0.026 & & & & \\
\hline Age (claims-based) & 0.973 & 0.930 & 1.017 & 0.223 & 0.973 & 0.923 & 1.025 & 0.301 \\
\hline \multicolumn{9}{|l|}{ Gender } \\
\hline Male & 0.582 & 0.404 & 0.840 & 0.004 & 0.443 & 0.291 & 0.673 & $<0.001$ \\
\hline Female & ref. & - & - & - & ref. & - & - & - \\
\hline
\end{tabular}

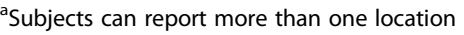

patients with only presenteeism or no work loss. Consistent with these findings, Singhal and colleagues, in a telephone survey of US patients identified in an administrative claims database, found that about half (51\%) reported missing work due to $\mathrm{HZ}$, and about an equal percentage reported little or much worse productivity than usual due to $\mathrm{HZ}$ while at work [4]. Drolet et al. [3] studied patients aged 50 years and older with HZ in Canada, and found that the majority (64\%) missed work and that $76 \%$ reported decreased effectiveness at work due to $\mathrm{HZ}$ and/or PHN Studies by Weinke [41] (Germany) and Lukas [42] (Europe) also found that work loss is an important issue for $\mathrm{HZ}$ patients, as approximately $50 \%$ of $\mathrm{HZ}$ patients who were employed at the time each study was conducted reported absences due to HZ/PHN. Since we were unable to identify any published studies that directly addressed the question of the impact of work loss on quality of life in $\mathrm{HZ}$, it is unknown whether $\mathrm{HZ}$ patients experiencing work loss rate themselves in worse health (i.e., map themselves into more severe EQ-5D health states) compared to other respondents who did not miss work, but are similar clinically.
It is important to consider our study's results in the context of several limitations. Generalizability of the results of this study may be limited, as our patient population was identified from one commercial managed care health plan, and thus may not be applicable to patients with other health care coverage. The health plan used for our analysis included a wide geographic distribution of patients across the United States, and therefore, should provide the capability for generalization to commercially insured managed care populations on a national level. However, $91 \%$ of patients in the current study were white, and we could not ascertain whether this is representative of health plan enrollment or if it represented response bias; regardless, our patient population is not representative of the racial composition of the US as a whole. Administrative claims are collected for payment rather than research purposes, and thus have some limitations related to the accuracy of capture of patient medical and pharmacy use history, and may also be subject to coding errors. Finally, patient survey data may be subject to recall bias, and it is also possible 
that patients with more severe HZ may be more likely to respond to the mailed survey.

\section{Conclusions}

HZ has considerable impact on the work and productivity of adults aged 50-64 years old. Consideration of lost time in paid work is associated with lower health status scores when patients complete a standardized quality of life questionnaire (e.g., EQ-5D). However, many patients with $\mathrm{HZ}$ do not spontaneously consider work/income loss when completing a standardized quality of life questionnaire. Studies that use health-state utilities in HZ, including those based on standardized scales such as EQ-5D, may not fully reflect the societal costs and consequences of work loss. Our study's findings suggest that it may be appropriate to account for this effect separately in cost calculations.

\section{Additional file}

Additional file 1: Appendix. Work absenteeism and presenteeism by considered work loss. Table describing absenteeism and presenteeism, productivity, and work loss. (DOCX $18 \mathrm{~kb}$ )

\section{Abbreviations}

B: Billion; Cl: Confidence interval; EQ-5D: EuroQol Five Dimensions Questionnaire; HIPAA: Health Insurance Portability and Accountability Act; HZ: Herpes zoster; ICD-9-CM: International Classification of Diseases, Ninth Revision, Clinical Modification; OR: Odds ratio; PHN: Post-herpetic neuralgia; SD: Standard deviation

\section{Acknowledgements}

The authors would like to acknowledge Jen Wogen, MedMentis Consulting LLC, for medical writing assistance on this manuscript.

\section{Funding}

This study was funded by Merck \& Co., Inc.

\section{Availability of data and materials}

The data contained in our database contains proprietary elements owned by Optum and, therefore, cannot be broadly disclosed or made publicly available at this time. The disclosure of this data to third party clients assumes certain data security and privacy protocols are in place and that the third party client has executed our standard license agreement which includes restrictive covenants governing the use of the data.

\section{Authors' contributions}

$S K B, L B$, and $A B$ participated in study design, analyzed and interpreted study data and contributed to manuscript writing and editing for content. KDJ, CJA, CN, and SSC contributed to study design, interpreted study data and contributed to manuscript content editing. All authors read and approved the final manuscript.

\section{Ethics approval and consent to participate}

Independent study approval was obtained from the New England Institutional Review Board (reference \# 15-133) and a waiver of documentation of informed consent was granted. The mailed study packet informed patients that their consent for participation was implied by returning the completed survey.

\section{Consent for publication}

Not applicable.

\section{Competing interests}

KDJ and CJA are employees of Merck \& Co., Inc. SSC was an employee of Merck \& Co., Inc. at the time the study was conducted but are no longer employed by Merck. CN was a contract employee of Merck \& Co., Inc. at the time the study was conducted.

\section{Publisher's Note}

Springer Nature remains neutral with regard to jurisdictional claims in published maps and institutional affiliations.

\section{Author details}

${ }^{1}$ Center for Observational and Real World Evidence (CORE), Merck \& Co., Inc, 351 North Sumneytown Pike, UG2AB-30, North Wales, PA 19454, USA. ${ }^{2}$ Health Economics and Outcomes Research, Optum, 11000 Optum Circle, Eden Prairie, MN 55344, USA. ${ }^{3}$ Merck Research Laboratories, 351 North Sumneytown Pike, North Wales, PA 19454, USA.

Received: 25 July 2017 Accepted: 7 August 2018

Published online: 25 August 2018

\section{References}

1. Yawn BP, Saddier P, Wollan PC, et al. A population-based study of the incidence and complication rates of herpes zoster before zoster vaccine introduction. Mayo Clin Proc. 2007:82:1341-9.

2. McLaughlin JM, McGinnis JJ, Tan L, et al. Estimated human and economic burden of four major adult vaccine-preventable diseases in the United States, 2013. J Prim Prev. 2015;36:259-73.

3. Drolet M, Levin MJ, Schmader KE, et al. Employment related productivity loss associated with herpes zoster and postherpetic neuralgia: a 6-month prospective study. Vaccine. 2012;30:2047-50.

4. Singhal PK, Makin C, Pellissier J, et al. Work and productivity loss related to herpes zoster. J Med Econ. 2011;14:639-45.

5. Drolet $M$, Brisson $M$, Levin $M J$, et al. A prospective study of the herpes zoster severity of illness. Clin J Pain. 2010;26:656-66.

6. Drolet M, Brisson M, Schmader KE, et al. The impact of herpes zoster and postherpetic neuralgia on health-related quality of life: a prospective study. CMAJ. 2010;182:1731-6.

7. Katz J, Cooper EM, Walther RR, et al. Acute pain in herpes zoster and its impact on health-related quality of life. Clin Infect Dis. 2004;39:342-8.

8. Schmader KE, Sloane R, Pieper C, et al. The impact of acute herpes zoster pain and discomfort on functional status and quality of life in older adults. Clin J Pain. 2007;23:490-6.

9. Merck \& Co. Inc. Zostavax (package insert). Whitehouse Station, NJ; 2011. http://www.merck.com/product/usa/pi_circulars/z/zostavax/zostavax_pi2. pdf. Accessed 15 Aug 2018.

10. Advisory Committee on Immunization Practices (US Centers for Disease Control and Prevention). Prevention of herpes zoster: recommendations of the Advisory Committee on Immunization Practices (ACIP). MMWR. 2008; RR-5. https://www.cdc.gov/mmwr/preview/mmwrhtml/rr57e0515a1.htm. Accessed 15 Aug 2018.

11. Kawai K, Gebremeskel BG, Acosta CJ. Systematic review of incidence and complications of herpes zoster: towards a global perspective. BMJ Open. 2014;4(6):e004833.

12. Schmader KE, Levin MJ, Gnann JW Jr, et al. Efficacy, safety, and tolerability of herpes zoster vaccine in persons aged 50-59 years. Clin Infect Dis. 2012; 54(7):922-8

13. Insinga RP, Itzler RF, Pellissier JM, et al. The incidence of herpes zoster in a United States administrative database. J Gen Intern Med. 2005;20(8):748-53.

14. US Department of Labor Bureau of Labor Statistics. Employment status of the civilian noninstitutionalized population by age, sex, and race. Washington DC: US Department of Labor Bureau of Labor Statistics; 2015.

15. Tilling C, Krol M, Tsuchiya A, et al. In or out? Income losses in health state valuations: a review. Value Health. 2010;13:298-305.

16. EuroQoL Group. EuroQol--a new facility for the measurement of healthrelated quality of life. Health Policy. 1990;16:199-208.

17. Brooks R. EuroQol: the current state of play. Health Policy. 1996:37:53-72.

18. Oster G, Harding G, Dukes E, et al. Pain, medication use, and health-related quality of life in older persons with postherpetic neuralgia: results from a population-based survey. J Pain. 2005;6:356-63.

19. Davidson T, Levin LA. Do individuals consider expected income when valuing health states? Int J Technol Assess Health Care. 2008;24:488-94. 
20. Krol M, Brouwer W, Sendi P. Productivity costs in health-state valuations: does explicit instruction matter? PharmacoEconomics. 2006;24:401-14.

21. Richardson J, Peacock SJ, lezzi A. Do quality-adjusted life years take account of lost income? Evidence from an Australian survey. Eur J Health Econ. 2009;10:103-9.

22. Sendi P, Brouwer WB. Is silence golden? A test of the incorporation of the effects of ill-health on income and leisure in health state valuations. Health Econ. 2005;14:643-7.

23. Brouwer WB, Grootenboer S, Sendi P. The incorporation of income and leisure in health state valuations when the measure is silent: an empirical inquiry into the sound of silence. Med Decis Mak. 2009;29:503-12.

24. Meltzer DO, Weckerle CE, Chang LM. Do people consider financial effects in answering quality of life questions. Med Decis Mak. 1999;19:717.

25. Tilling C, Krol M, Trichiya A, et al. The impact of losses in income due to illhealth: does the EQ-5D reflect lost earnings? MPRA Paper University Library Munich 29837, 2009. https://mpra.ub.uni-muenchen.de/29837/1/ MPRA_paper_29837.pdf. Accessed 15 Aug 2018.

26. Tilling C, Krol M, Tsuchiya A, et al. Does the EQ-5D reflect lost earnings? PharmacoEconomics. 2012;30:47-61.

27. Krol M, Sendi P, Brouwer W. Breaking the silence: exploring the potential effects of explicit instructions on incorporating income and leisure in TTO exercises. Value Health. 2009;12:172-80.

28. Shiroiwa T, Fukuda T, Ikeda S, et al. QALY and productivity loss: empirical evidence for "double counting". Value Health. 2013;16:581-7.

29. Frederix GW, Quadri N, Hovels AM, et al. Utility and work productivity data for economic evaluation of breast cancer therapies in the Netherlands and Sweden. Clin Ther. 2013;35:e1-7.

30. Dillman DA, Smyth JD, Christian LM. Internet, mail, and mixed-mode surveys. The tailored design method. 3rd ed. Hoboken, NJ: John Wiley \& Sons, Inc:; 2009.

31. EuroQoL Group. EQ-5D User Guide, version 5.02013. www.eurogol.org. Accessed 17 Mar 2016.

32. Shaw JW, Johnson JA, Coons SJ. US valuation of the EQ-5D health states: development and testing of the D1 valuation model. Med Care. 2005;43: 203-20

33. Quan H, Li B, Couris CM, et al. Updating and validating the Charlson comorbidity index and score for risk adjustment in hospital discharge abstracts using data from 6 countries. Am J Epidemiol. 2011;173:676-82.

34. Agency for Healthcare Research and Quality. HCUP Comorbidity Software: Health Cost and Utilization Project (HCUP). 2009.

35. American Association for Public Opinion Research. Standard definitions: final dispositions and case codes and outcome rates for surveys. Deerfield, IL: American Association for Public Opinion Research; 2008.

36. Myers J, McCabe S, Gohmann S. Quality-of-life assessment when there is a loss of income. Med Decis Mak. 2007:27:27-33.

37. Melzter D, Weckerle CE, Chang LM. Do people consider financial effects in answering quality of life questions? Med Decis Making. 1999;19:517.

38. Gater A, Abetz-Webb L, Carroll S, et al. Burden of herpes zoster in the UK: findings from the zoster quality of life (ZQOL) study. BMC Infect Dis. 2014; 14:402.

39. Serpell M, Gater A, Carroll S, et al. Burden of post-herpetic neuralgia in a sample of UK residents aged 50 years or older: findings from the zoster quality of life (ZQOL) study. Health Qual Life Outcomes. 2014;12:92.

40. van Seventer R, Sadosky A, Lucero M, et al. A cross-sectional survey of health state impairment and treatment patterns in patients with postherpetic neuralgia. Age Ageing. 2006;35:132-7.

41. Weinke T, Edte A, Schmitt S, et al. Impact of herpes zoster and post-herpetic neuralgia on patients' quality of life: a patient-reported outcomes survey. Z Gesundh Wiss. 2010;18:367-74.

42. Lukas K, Edte A, Bertrand I. The impact of herpes zoster and post-herpetic neuralgia on quality of life: patient-reported outcomes in six European countries. Z Gesundh Wiss. 2012:20:441-51.

\section{Ready to submit your research? Choose BMC and benefit from:}

- fast, convenient online submission

- thorough peer review by experienced researchers in your field

- rapid publication on acceptance

- support for research data, including large and complex data types

- gold Open Access which fosters wider collaboration and increased citations

- maximum visibility for your research: over $100 \mathrm{M}$ website views per year

At BMC, research is always in progress.

Learn more biomedcentral.com/submissions 